\title{
Diagnosis of cutaneous anthrax in resource-poor settings in West Arsi Province, Ethiopia
}

\author{
Ramón Pérez-Tanoira' ${ }^{1,2, A-F}$, Jose Manuel Ramos ${ }^{1,3, A-F}$, Laura Prieto-Pérez ${ }^{1,2, A-F}$,

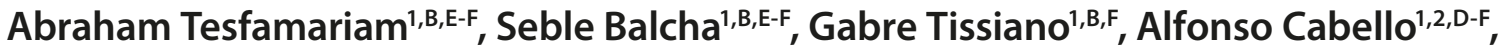 \\ Juan Cuadros ${ }^{1,4, D-F}$, Natalia Rodríguez-Valero ${ }^{5, B, E-F}$, Pablo Barreiro ${ }^{6, B, E-F}$, Francisco Reyes ${ }^{1, B, E-F}$, \\ Miguel Górgolas ${ }^{1,2, A-F}$ \\ ${ }^{1}$ Gambo Rural General Hospital, Kore, West-Arsi, Gambo, Ethiopia \\ ${ }^{2}$ Division of Infectious Diseases, IIS-Fundación Jiménez Díaz \& Universidad Autónoma de Madrid, Madrid, Spain \\ ${ }^{3}$ Department of Internal Medicine, Hospital General Universitario de Alicante \&Universidad Miguel Hernández de Elche; \\ Alicante, Spain \\ ${ }^{4}$ Department of Clinical Microbiology, Hospital Universitario Príncipe de Asturias \& Universidad de Alcala de Henares, \\ Alcalá de Henares, Spain \\ ${ }^{5}$ Tropical Medicine Unit, Hospital Clinic, Barcelona, Spain \\ ${ }^{6}$ Tropical and Travel Medicine Unit. Hospital Carlos III - La Paz. Madrid, Spain \\ A - Research concept and design, B - Collection and/or assembly of data, C - Data analysis and interpretation, \\ $D$ - Writing the article, E-Critical revision of the article, F- Final approval of article
}

Pérez-Tanoira R, Ramos JM, Prieto-Pérez L, Tesfamariam A, Balcha S, Tissiano G, Cabello A, Cuadros J, Rodríguez-Valero N, Barreiro P, Reyes F, Górgolas M. Diagnosis of cutaneous anthrax in resource-poor settings in West Arsi Province, Ethiopia. Ann Agric Environ Med. 2017; 24(4): 712-715. doi: $10.26444 /$ aaem/80705

\section{Abstract}

Introduction. Cutaneous anthrax is a zoonotic disease caused by the spore-forming bacterium Bacillus anthracis, which typically presents with ulcers after contact with animals or animal products, and is rarely seen in high-income countries but is common in those with low- and middle-incomes.

Objective. The aim of this study is to show the main clinical characteristics of cutaneous anthrax in endemic areas.

Materials and method. The study describes the main clinical characteristics of cutaneous anthrax in eight patients (six female and two male, age range 1 - 56 years) admitted to the rural General Hospital of Gambo, West Arsi Province of Ethiopia from 2010-2013.

Results. In all cases, lesions began as an erythematous papule located on exposed sites $(n=7$ head; $n=1$ thigh) and subsequently became a necrotic black eschar surrounded by an edematous halo. Two patients presented with painful ipsilateral adenopathy near the black eschar. Four patients developed a malignant pustule on the suborbital region of the face. Patients responded positively to treatment, and the lesions resolved, leaving eschars. However, one patient suffered the loss of an eyeball, and another died 12 hours after starting treatment.

Conclusions. Physicians working in rural areas of resource-poor settings should be trained in the clinical identification of cutaneous anthrax. Early antibiotic treatment is essential for decreasing morbidity and mortality.

\section{Key words}

Bacillus anthracis, cutaneous anthrax, Ethiopia

\section{INTRODUCTION}

Virgil's plague, or anthrax, is a zoonotic disease caused by the spore-forming bacterium Bacillus anthracis. Anthrax toxins, together with an antiphagocytic polyglutamic capsule, are the bacterium's main virulence factors. Considered an occupational disease, it is rarely seen in high-income countries but is common in rural areas of low- and middleincome countries [1]. B.anthracis is a biological agent that may be used in bioterrorism attacks [2].

Anthrax has three major clinical forms: gastrointestinal, cutaneous, and inhalational. The early symptoms of gastrointestinal and inhalational anthrax can be nonspecific and mistaken for less serious conditions $[3,4]$, patients therefore often present with an advanced infection that can

Address for correspondence: Ramón Pérez-Tanoira Gambo Rural General Hospital Kore, West-Arsi, Gambo, Ethiopia, Av. reyes Católicos 2, 28040 Madrid, Spain E-mail: ramontanoira@hotmail.com

Received: 04.11.2017; accepted: 21.11.2017; first published: 11.12.2017 be highly lethal. However, the most common form by far of the disease is cutaneous, accounting for about $95 \%$ of cases, and its early stages are distinctly recognizable. With prompt, appropriate treatment, a good outcome is very likely.

Almost all cases of anthrax in humans are directly related to contact with infected animals, especially with cattle, although cases may also arise from indirect contact with heavily contaminated soil. People working with carcasses - particularly of animals that died suddenly - are most at risk, for example, slaughterhouse workers, farmers and veterinarians.

\section{OBJECTIVES}

A systematic review was conducted to describe the main clinical characteristics of eight cases of cutaneous anthrax in a resource-poor setting without microbiological facilities for proper diagnosis. 


\section{MATERIALS AND METHOD}

A descriptive, retrospective cross-sectional study was carried out of eight cases of cutaneous anthrax, diagnosed at the Gambo General Hospital (GGH) in Ethiopia between 20102013. The hospital is located in the West Arsi Province, $245 \mathrm{~km}$ southeast of the capital city, Addis Ababa, located at an altitude of $2,250 \mathrm{~m}$ above sea level $\left(7^{\circ} 18^{\prime} 22.4^{\prime \prime} \mathrm{N}+38^{\circ} 48^{\prime} 54.7^{\prime \prime} \mathrm{E}\right)$. The catchment area of the GGH comprises approximately 100,000 inhabitants, most of whom live in a rural setting and work in agriculture and farming.

Diagnosis of the anthrax cases was generally based on the clinical aspect of the lesions, together with epidemiological data (contact with animals or animal products). Microbiological diagnosis was not available. A culture was taken to identify the microorganism in just one of the eight cases. Two cases (Case 4 and Case 7) have been described in previous case reports $[5,6]$.

The study was approved by the Ethical Review Board at Gambo Hospital.

\section{RESULTS}

Six female and two male patients (age range 1-56 years) with a history of close contact with animals were admitted with ulcers covered by a characteristic black eschar. The incubation

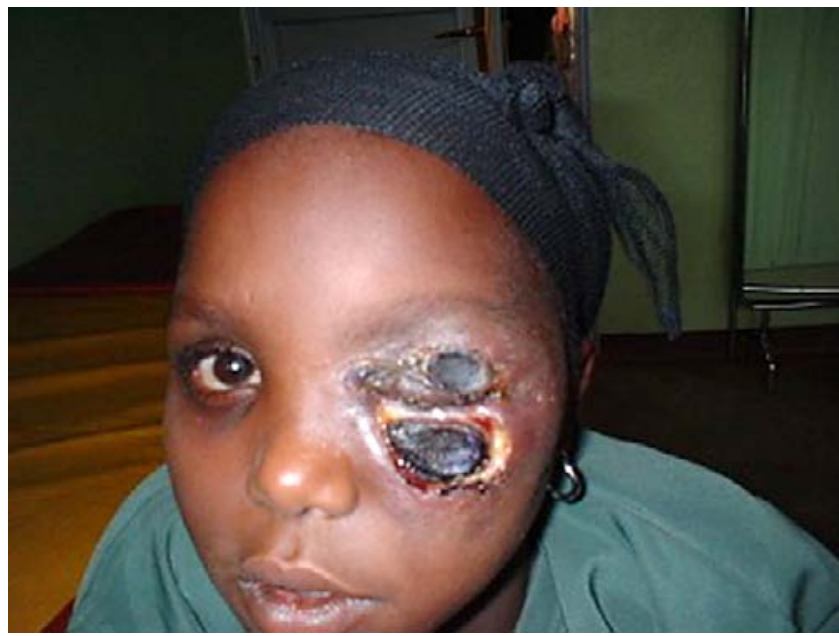

Figure 1. Black eschar with reduction of periorbital edema and loss of the eyeball period was from 1 day (Case 4) to 5 days (case 3). The source of infection was contact with sick sheep or cattle in six cases, and consumption of contaminated meat in two cases (Case 1 and Case 4). The lattter two cases were related to an outbreak of cutaneous anthrax. Table 1 shows patients' demographic, epidemiological and clinical characteristics.

All patients reported having a fever, but only one was febrile during hospitalization (Case 3). Seven patients were brought to the emergency room due to black eschar; five patients showed oedema when examined in the hospital (Cases 1, $2,4,7$ and 8$)$. Lesions were located on the head $(n=7)$ and thigh $(n=1)$. Four patients showed periocular lesions (Cases 1, 2, 5 and 8), and one patient, bilateral ocular purulent discharge (Case 3). A malignant pustule eventually developed on the suborbital region of the face in two patients (Fig. 1). In all cases, lesions began as an erythematous papule on the exposed sites, and subsequently evolved into a necrotic black eschar surrounded by an oedematous halo. Only two patients reported painful ipsilateral adenopathy in the cervical (Case 6) (Fig. 2) or femoral (Case 7) lymph nodes. One patient was also co-infected with measles.

The patients were treated as follows:

a) combined treatment of intravenous (IV) penicillin G and ciprofloxacin for 6 days $(n=4)$ or IV penicillin $G$ alone for 7 to 10 days $(n=2)$,

b) intramuscular (IM) ceftriaxone plus topical azithromycin for periocular affectation $(n=1)$,

c) IM penicillin $\mathrm{G}$ procaine $(\mathrm{n}=1)$.

The latter patient (Case 4) died 12 hours after starting treatment due to laryngeal Oedema. Seven (87.5\%) patients responded to antibiotics, and the lesions resolved, leaving eschar. The patient whose eyelids were affected lost one eye (case 5).

\section{DISCUSSION}

About $80 \%$ of Ethiopians depend on agriculture and have direct contact with livestock or other domestic animals, making the country vulnerable to the spread of zoonotic diseases. As the first step in the country's engagement in the Global Health Security Agenda, a zoonotic disease workshop identified five priority zoonotic diseases of mutual concern for animal and human health agencies: rabies, anthrax, brucellosis, leptospirosis, and echinococcosis [7].

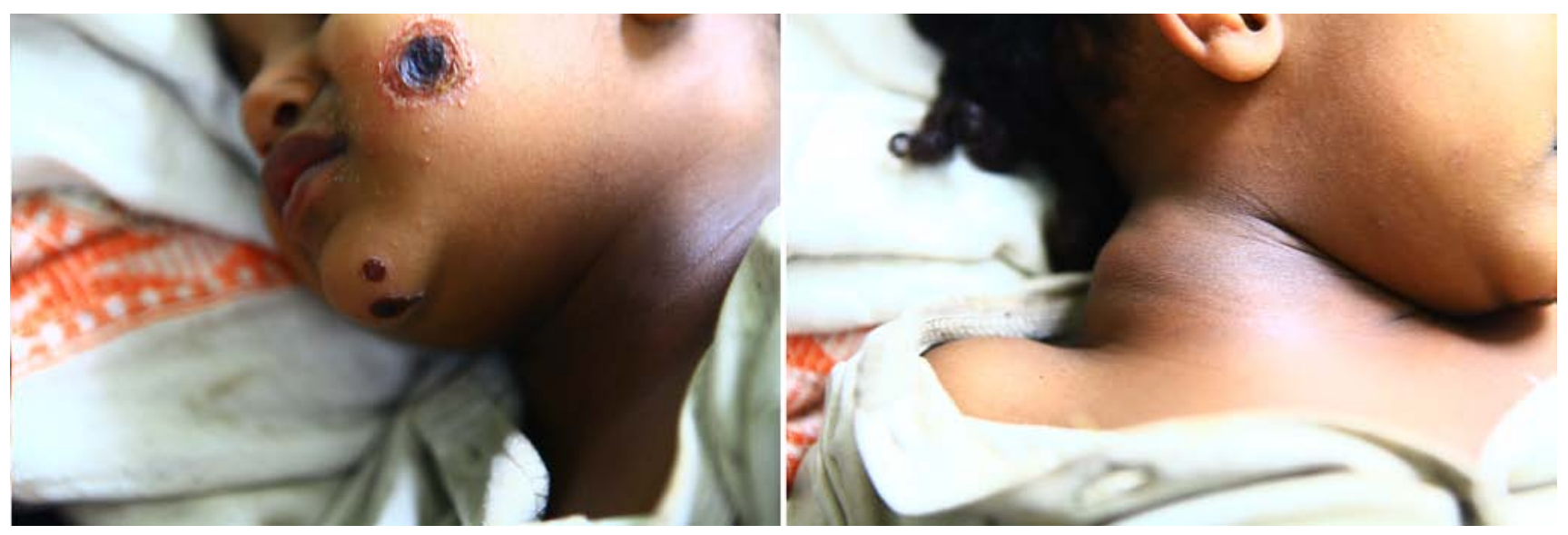

Figure 2. Black eschar in face and painful ipsilateral adenopathy in the cervical lymph nodes 
Table 1. Clinical and epidemiological data on patients suffering from cutaneous anthrax

\begin{tabular}{|c|c|c|c|c|c|c|c|c|c|c|c|c|}
\hline Case & $\begin{array}{l}\text { Age }(y) / \\
\text { gender }\end{array}$ & $\begin{array}{l}\text { Duration of } \\
\text { incubation } \\
\text { period (days) }\end{array}$ & $\begin{array}{c}\text { Source } \\
\text { of } \\
\text { infection* }\end{array}$ & Location & Oedema & Eschar & $\begin{array}{l}\text { Lymph } \\
\text { node }\end{array}$ & Fever & Outbreak & Treatment & Severity of infection & $\begin{array}{l}\text { Outcome/ } \\
\text { sequalae }\end{array}$ \\
\hline 1 & $45 / F$ & 2 & 1 & $\begin{array}{l}\text { Periocular } \\
\text { and face }\end{array}$ & Y & Y & $\mathrm{N}$ & $\mathrm{N}$ & Y & $\begin{array}{l}\text { Ciprofloxacin (PO)+ } \\
\text { Penicillin G (IV) }\end{array}$ & $\begin{array}{c}\text { Severe cutaneous } \\
\text { anthrax, toxemic shock, } \\
\text { extensive edema }\end{array}$ & Recovery \\
\hline 2 & $\begin{array}{l}1 / \\
M\end{array}$ & 5 & 2 & $\begin{array}{l}\text { Periocular } \\
\text { and face }\end{array}$ & Y & Y & $\mathrm{N}$ & $\mathrm{N}$ & $\mathrm{N}$ & $\begin{array}{l}\text { Ciprofloxacin (PO)+ } \\
\text { Penicillin G (IV) }\end{array}$ & Mild cutaneous anthrax & Recovery \\
\hline 3 & $\begin{array}{l}2 / \\
\mathrm{F}\end{array}$ & 3 & 2 & $\begin{array}{l}\text { Anterior } \\
\text { head and } \\
\text { bilateral } \\
\text { ocular }\end{array}$ & $\mathrm{N}$ & Y & $\mathrm{N}$ & Y & $\mathrm{N}$ & $\begin{array}{c}\text { Ceftriaxone } \\
\text { + topical } \\
\text { azithromycin (eye } \\
\text { drops) }\end{array}$ & $\begin{array}{l}\text { Mild cutaneous anthrax } \\
\text { and measles }\end{array}$ & Recovery \\
\hline 4 & $30 / F$ & 1 & 1 & $\begin{array}{l}\text { Lips, lower } \\
\text { face and } \\
\text { neck }\end{array}$ & Y & $\mathrm{N}$ & $\mathrm{N}$ & $\mathrm{N}$ & Y & $\begin{array}{l}\text { Procaine penicillin } \\
\text { (IM) }\end{array}$ & $\begin{array}{c}\text { Severe cutaneous } \\
\text { anthrax, toxemic shock } \\
\text { and extensive edema }\end{array}$ & Death \\
\hline 5 & $10 / F$ & 4 & 2 & Left eye & $\mathrm{N}$ & Y & $\mathrm{N}$ & $\mathrm{N}$ & $\mathrm{N}$ & $\begin{array}{c}\text { Ciprofloxacin (PO)+ } \\
\text { Penicillin G (IV) } \\
+ \text { topical } \\
\text { azithromycin }\end{array}$ & $\begin{array}{l}\text { Severe cutaneous } \\
\text { anthrax }\end{array}$ & $\begin{array}{c}\text { Loss of } \\
\text { eyeball and } \\
\text { deep scarring }\end{array}$ \\
\hline 6 & $7 / F$ & 4 & 2 & Left face & $\mathrm{N}$ & Y & Cervical & $\mathrm{N}$ & $\mathrm{N}$ & Penicillin G (IV) & Mild cutaneous anthrax & Recovery \\
\hline 7 & $1 / \mathrm{M}$ & 4 & 2 & Left thigh & $\mathrm{Y}$ & Y & Femoral & $\mathrm{N}$ & $\mathrm{N}$ & Penicillin G (IV) & Mild cutaneous anthrax & Recovery \\
\hline 8 & $53 / F$ & 5 & 2 & $\begin{array}{l}\text { Both } \\
\text { eyelids }\end{array}$ & $\mathrm{Y}$ & Y & $\mathrm{N}$ & $\mathrm{N}$ & $\mathrm{N}$ & $\begin{array}{l}\text { Ciprofloxacin (PO)+ } \\
\text { Penicillin G (IV) }\end{array}$ & Mild cutaneous anthrax & $\begin{array}{l}\text { Deep } \\
\text { periocular } \\
\text { scarring }\end{array}$ \\
\hline
\end{tabular}

F-female; M - male; N - no; Y -yes; PO - orally; IV - intravenous; IM - intramuscular

* Source of infection: 1 - contaminated meat; 2 - contact with sick sheep or cattle.

Cutaneous anthrax mostly occurs on areas of exposed skin, with the face, neck, eyelid, and forearms constituting the most common infection sites $[3,4]$. When $B$. anthracis vegetative cells are exposed to air, they become spores that are highly resistant to both heat and to most disinfectants. For this reason, it is necessary to avoid exposing bacteria from dead anthrax-infected animals to oxygen, as the blood does not clot but instead drains from the natural orifices, e.g. nose, mouth, and bowel, contaminating soil and water with $B$. anthracis. These spores can remain viable for years in processed parts and products, such as leather, hides, wool, etc., and in the environment, especially when deposited at least $15 \mathrm{~cm}$ below the upper soil level [8].

Rapid and accurate diagnosis of cutaneous anthrax is crucial for successful treatment and in developing epidemiological strategies to halt the further spread and to control the disease [8-10]. Diagnosis may be microbiological, employing traditional methods, such as gram-staining, capsule staining from the smear of the lesion, or culturing of $B$. anthracis on sheep blood agar (5\%) and other routine culture media [8-10]. However, despite the existence of many molecular tests for anthrax, these systems are difficult to deploy with available resources in distant locations where anthrax is endemic [11]. Therefore, rapid, user-friendly, inexpensive serodiagnostic tests can be important tools for the surveillance of anthrax, minimizing agriculture- or occupation-related cases.

In basic rural laboratories without specialized infrastructure or periodic training for lab technicians, diagnosis of cutaneous anthrax is usually based on the clinical aspect of the lesions. However, these may be confused with ecthyma, cutaneous leishmaniasis, or other rare infections associated with black eschar - scrub typhus, rat bite fever, tularemia, or brown recluse spider bites [12]. Medical practitioners in rural health facilities have poor knowledge of the clinical features of anthrax and rabies in humans compared to their urban counterparts, which can contribute to under-diagnosis and consequent under-reporting [13].

Previous World Health Assembly (WHA) resolutions make little mention of any of the following neglected zoonotic diseases (NZDs), as defined by the World Health Organization (WHO): anthrax, bovine tuberculosis, brucellosis, leptospirosis, Taenia solium, cysticercosis, cystic echinococcosis (hydatidosis), leishmaniasis, rabies, and zoonotic human African trypanosomiasis (HAT or sleeping sickness). The recent adoption of a specific resolution at the WHA in 2013, promoting a One Health approach for the successful control of a specific group of neglected tropical diseases, is a major development in advocacy. However, recognition of the public health importance of three major NZDs (anthrax, brucellosis, and bovine tuberculosis) in countries where the diseases are endemic, is still lacking, despite being a WHO priority since as early as the 1950s. Global advocacy for NZD control would similarly benefit from the One Health approach adopted for the NTDs under the WHA [11].

\section{CONCLUSIONS}

Cutaneous anthrax caused by B. anthracis is still an endemic disease with an important public health impact in Ethiopia and elsewhere in Asia, Africa, and Europe. In the current cases, cutaneous anthrax presented as erythematous papules located on exposed sites and subsequently evolved into necrotic black eschars surrounded by an oedematous halo. Periorbital affectation was common. Symptoms resolved after prompt antibiotic therapy, underlining the relevance of early treatment for decreasing morbidity and mortality. Indeed, if left undiagnosed for too long, cutaneous anthrax can be fatal. Physicians working in rural areas of resource-poor settings should be trained in the clinical identification of this disease. 


\section{Acknowledgments}

The authors express their thanks all the members of the laboratory and clinical staff at the Gambo General Rural Hospital. The study was funded by the Master of Tropical Diseases and International Health of the Department of Medicine, held by the Universidad Autónoma of Madrid. We thank especially Dr. Francisco Reyes, managing director of Gambo Hospital.

\section{REFERENCES}

1. Moayeri M, Leppla SH, Vrentas C, Pomerantsev AP, Liu S. Anthrax Pathogenesis. Annu Rev Microbiol. 2015; 69: 185-208.

2. Żakowska D, Bartoszcze M, Niemcewicz M, Bielawska-Drózd A, Knap J, Cieślik P et al. Bacillus anthracis infections--new possibilities of treatment. Ann Agric Environ Med. 2015; 22: 202-207.

3. Gelaw Y, Asaminew T. Periocular cutaneous anthrax in Jimma Zone, Southwest Ethiopia: a case series. BMC Res Notes. 2013; 6: 313.

4. Gilliland G, Starks V, Vrcek I, Gilliland C. Periorbital cellulitis due to cutaneous anthrax. Int Ophthalmol. 2015; 35: 843-845.
5. Rodríguez-Valero N, Esquivias M, Plans E, Tesfamariam A, ReyesRabell F, Ramos-Rincón JM. Anthrax outbreak in a rural area of Ethiopia. Rev Clin Esp. 2012; 212: e73-5.

6. Pérez-Tanoira R, Cuadros J, Prieto-Pérez L. Black Eschar in the Highlands of Ethiopia. Am J Trop Med Hyg. 2016; 95: 737-738.

7. Pieracci EG, Hall AJ, Gharpure R, Haile A, Walelign E, Deressa A, et al. Prioritizing zoonotic diseases in Ethiopia using a one health approach. One Health. 2016; 2: 131-135.

8. Goel AK. Anthrax: A disease of biowarfare and public health importance. World J Clin Cases. 2015; 3: 20-33.

9. Ivins BE, Welkos SL, Little SF, Crumrine MH, Nelson GO. Immunization against anthrax with Bacillus anthracis protective antigen combined with adjuvants. Infect Immun. 1992; 60: 662-668.

10. Iacono-Connors LC, Welkos SL, Ivins BE, Dalrymple JM.Protection against anthrax with recombinant virus-expressed protective antigen in experimental animals. Infect Immun. 1991; 59: 1961-1965.

11. Mableson HE, Okello A, Picozzi K, Welburn SC. Neglected zoonotic diseases-the long and winding road to advocacy. PLoSNegl Trop Dis. 2014; 8: e2800.

12. Liu S, Moayeri M, Leppla SH. Anthrax lethal and edema toxins in anthrax pathogenesis. Trends Microbiol. 2014; 22: 317-325.

13. John K, Kazwala R, Mfinanga GS. Knowledge of causes, clinical features and diagnosis of common zoonoses among medical practitioners in Tanzania. BMC Infect Dis. 2008; 8: 162. 